\title{
CARACTERIZAÇÃO MICROESTRUTURAL DE JUNTA SOLDADA DE AÇO ASTM A - 131M EH-36 UTILIZADO EM TUBULAÇÕES DE PETRÓLEO E GÁS
}

\author{
SILVA, Helio Batista ${ }^{1}$
}

RESUMO: RESUMO: Este trabalho visa à caracterização de uma junta soldada de tubo de aço ASTM A - 131M EH-36. A caracterização micro e macro estrutural das amostras foram realizados por microscopia ótica e microscopia eletrônica de varredura. As propriedades mecânicas da junta soldada foram analisadas por ensaio de micro dureza. Os resultados mostram uma matriz de grãos ferríticos, alternados com bandas perlíticas alinhadas paralelamente à direção de laminação da chapa, na ZAC foi observada a formação de ferrita acicular, ferrita poligonal e bainita. O ensaio de dureza mostrou que há um aumento na dureza do metal base para a zona fundida como já era esperado.

Palavras-Chave: Aço ASTM A - 131M EH-36. Aços Estrutural. Soldagem

SUMMARY: This work aims the characterization of welded joint of steel pipe ASTM A - 131m EH -36. The micro and macro structural characterization of samples were performed by optical microscopy and scanning electron microscopy. The mechanical properties of welded joint were analyzed by micro hardness testing. The results show a matrix of ferritic grains alternating with pearlitic bands aligned parallel to the sheet rolling direction on the HAZ was observed formation of acicular ferrite, polygonal ferrite and bainite. The hardness test showed that there is an increase in base metal hardness to the molten zone as expected.

Keywords: Steel ASTM A - 131m EH36. Structural steel. Welding

\section{INTRODUÇÃO}

No Brasil a demanda energética apresenta uma projeção crescente, levando em conta o cenário de crescimento do país, projeção de reservas e intenções de investimentos da produção de gás natural, estimase que em 2030 a produção pode chegar a 251,7 milhões de $\mathrm{m} 3$ /dia com crescimento de 5\% ano, enquanto que o consumo pode chegar a $4 \%$ ao ano. $\mathrm{O}$ que faz com que se intensifiquem os investimentos no setor de petróleo e gás, este fato justifica a procura por novos materiais e/ou técnicas que permitam menor custo para montagem de manutenção. Materiais utilizados no transporte de petróleo e gás são especificados pelo Instituto Americano de Petróleo (API) sendo o aço em estudo classificado pelas normas American Standard ASTM. A norma ASTM A - 131M apresenta as características do aço EH-36, utilizado na construção naval, plataformas marítimas e tubulações de gás e petróleo. Dentro deste cenário umas das etapas fundamentais de projeto mecânico a conhecer são os efeitos dos processos soldagem na formação metalúrgica das juntas soldadas. Na etapa de soldagem há alterações na microestrutura do aço o que pode resultar em perdas de propriedades químicas e físicas, desta forma dependendo do grau da alteração pode-se comprometer o projeto como um todo. Na literatura foram encontrados poucos trabalhos que abordam sobre a soldabilidade do aço EH-36, portanto devido à complexidade dos fenômenos envolvidos, um estudo científico é de estrema importância. Este trabalho visa avaliar os efeitos da soldagem por arame tubular na microestrutura de uma junta soldada do aço EH-36 e seus efeitos na propriedade de dureza, desta forma, contribuindo com dados que possam auxiliar na prevenção de uma possível falha.

${ }^{1}$ UNIVESP - FATEC Faculdade de Tecnologia Itaquera. 


\section{MATERIAL E MÉTODO}

\section{Materiais}

Foi analisada uma junta que foi doada por uma empresa da área de soldagem, trata-se de uma junta de tubulação de aço estrutural EH-36, soldada por arame tubular. A tabela apresenta as características químicas do aço EH-36, conforme norma ASTM A131M.

Tabela 1. Caracteristicas químicas do metal base.

\begin{tabular}{|c|c|c|c|c|c|c|c|c|c|c|c|c|}
\hline $\mathrm{C}$ & Mn & $\mathbf{S i}$ & $P / S$ & $\overline{\mathbf{A L}}$ & $\mathbf{C b}$ & $\mathbf{V}$ & $\mathbf{T i}$ & $\mathbf{C u}$ & $\mathrm{Cr}$ & $\mathbf{N i}$ & Mo & $\mathbf{N}$ \\
\hline 0,18 & $\begin{array}{l}0,9- \\
1,6\end{array}$ & $\begin{array}{l}0,1- \\
0,5\end{array}$ & $\mathbf{0 , 0 4}$ & $\mathbf{0 , 0 1 5}$ & $\begin{array}{l}0,02- \\
0,05\end{array}$ & $\begin{array}{l}0,05- \\
0,1\end{array}$ & $\mathbf{0 , 0 2}$ & $\mathbf{0 , 3 5}$ & $\mathbf{0 , 2 0}$ & $\mathbf{0 , 4 0}$ & $\mathbf{0 , 0 8}$ & - \\
\hline
\end{tabular}

Figura 1. Caracterização por microscopia ótica.
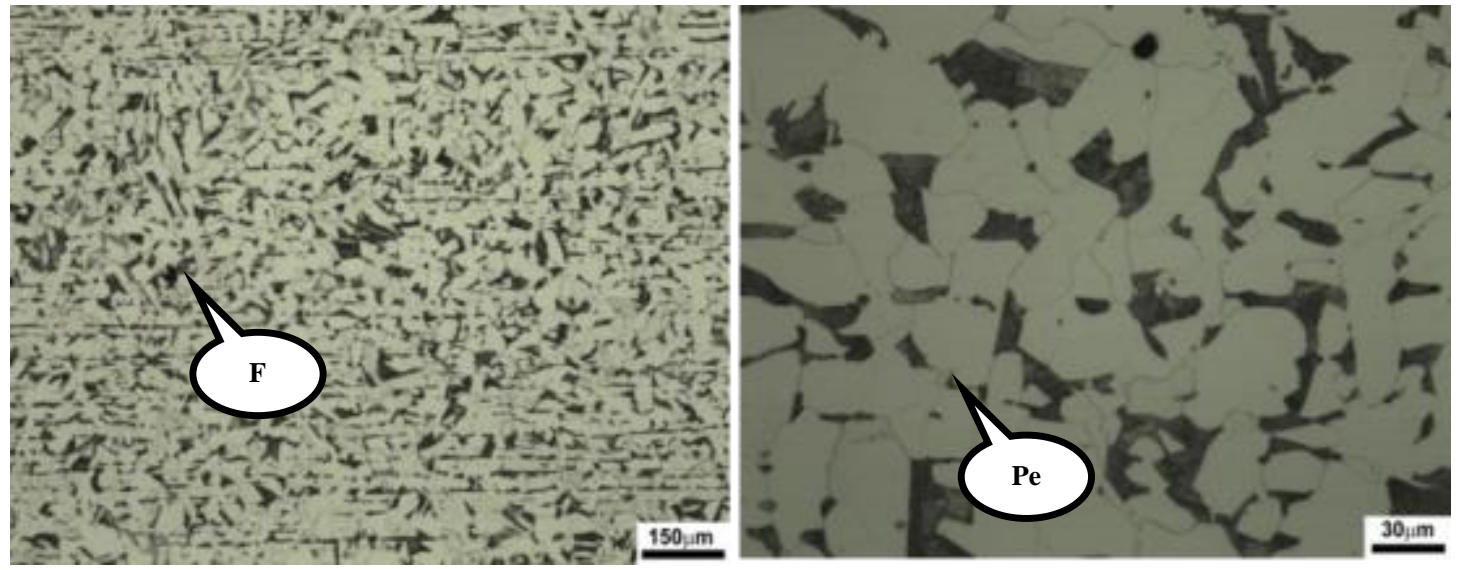

As imagens da microestrutura do metal de base, com ataque nital $2 \%$ apresentadas nas figuras acimas mostram que o metal base é composto basicamente por ferrita e Perlita, sendo esta formada na decomposição eutetoide apresentando lamelas justapostas de ferrita e cementita. Também é possível observar a formação de estruturas orientadas no sentido de orientação da chapa (grão de ferrita alongados). A quantificação do microconstituinte perlita mostra que há cerca de $19 \%$ deste microconstituinte. A Figura apresenta imagens de microscopia eletrônica da região do metal base. 


\section{METODOS}

Metal base

Figura 2. Microestrutura do metal de base
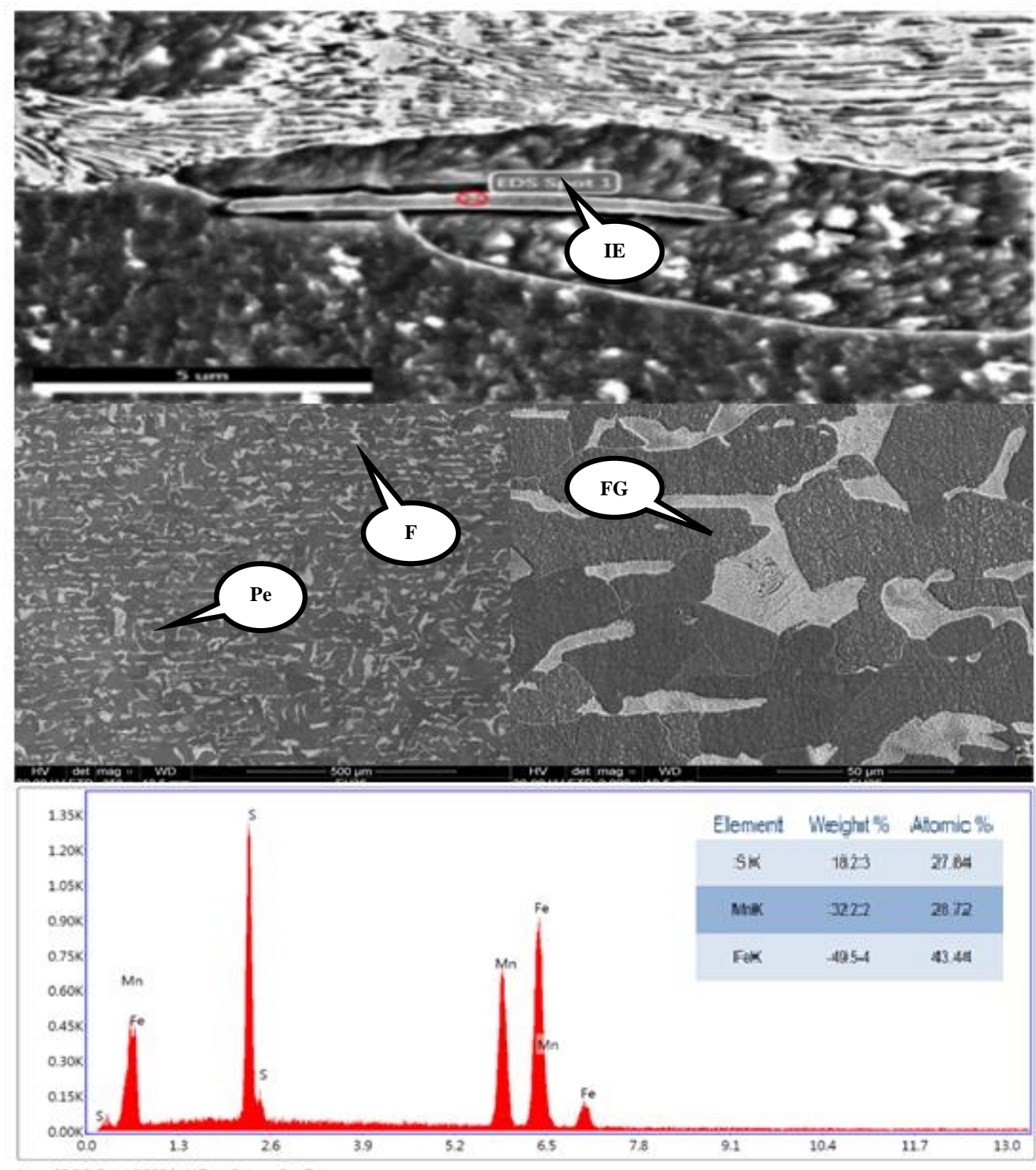

Lses: 30.00 Cnts 0.000 keV Det Octane Pro Det

É possível observar nas imagens de MEV da região do metal base a presença do microconstituinte perlita $(\mathrm{Pe})$ e da fase ferrita (F). Também é possível observar a presença de filme de carboneto no contorno de grão da fase ferrita (FG). A micro análise química por EDS realizada na inclusão observada na imagem acima indica a presença de inclusões de sulfeto de manganês (IE). 


\section{Zona de ligação}

Figura 3. Microestrutura zona de ligação.


As imagens de microscopia ótica obtidas na zona de ligação são possíveis observar a presença ferrita poligonal (FP), ferrita Acicular (FA), Ferrita de contorno de grão (FG) e bainita. Esses resultados corroboram com os obtidos em trabalhos encontrados na literatura (ARAUJO, 2008). As imagens de microscopia eletrônica de varredura indicam a presença de carbonetos e também foi verificada a presença de inclusões.

\section{Zona fundida}

Figura 4. Microestrutura de zona fundida.
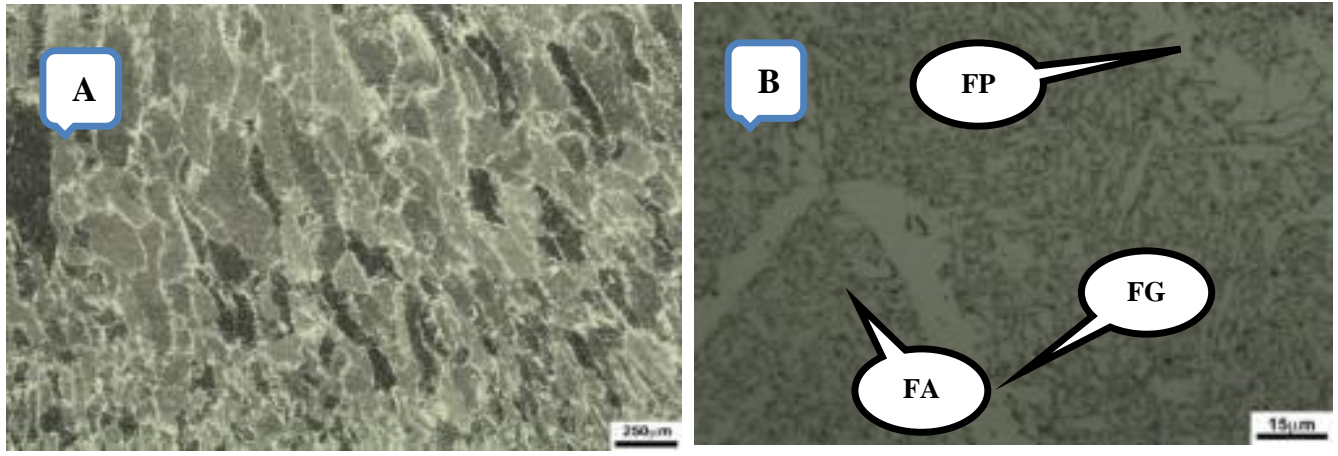

A micrografia ótica apresentada na figura acima A é possível observar o crescimento colunar durante a solidificação do cordão, também é possível verificar este crescimento se deu pelo mecanismo de crescimento epitaxial uma vez que o grão seguem as mesmas orientações dos grãos anteriores. A microestrutura apresentada na figura B é possível observar a presença de ferrita de contorno de grão (FG) e ferrita acicular (FA) e ferrita poligonal (FP). 
Figura 5. Região de grão fino.
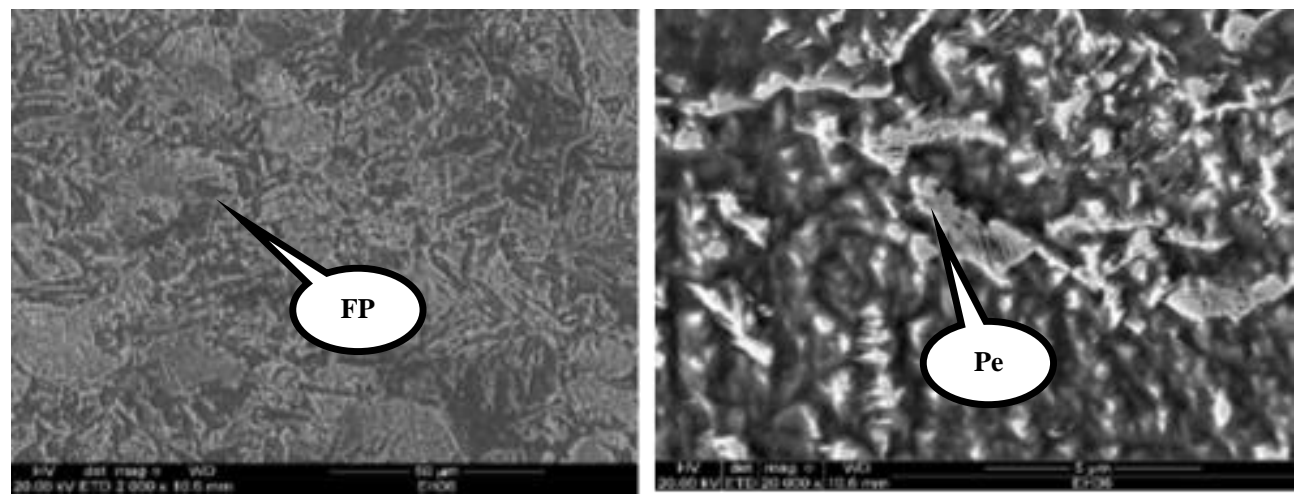

Nas observa-se grãos finos de ferríta poligonais (FP), a presença de grãos finos de ferrita, que podem ser consequência do ciclo térmico dentro da zona crítica, também é observado a presença de microconstituinte Perlita (Pe) na forma lamelar nucleando no contorno de grão

Figura 6. Microestrutura de grãos grossos.
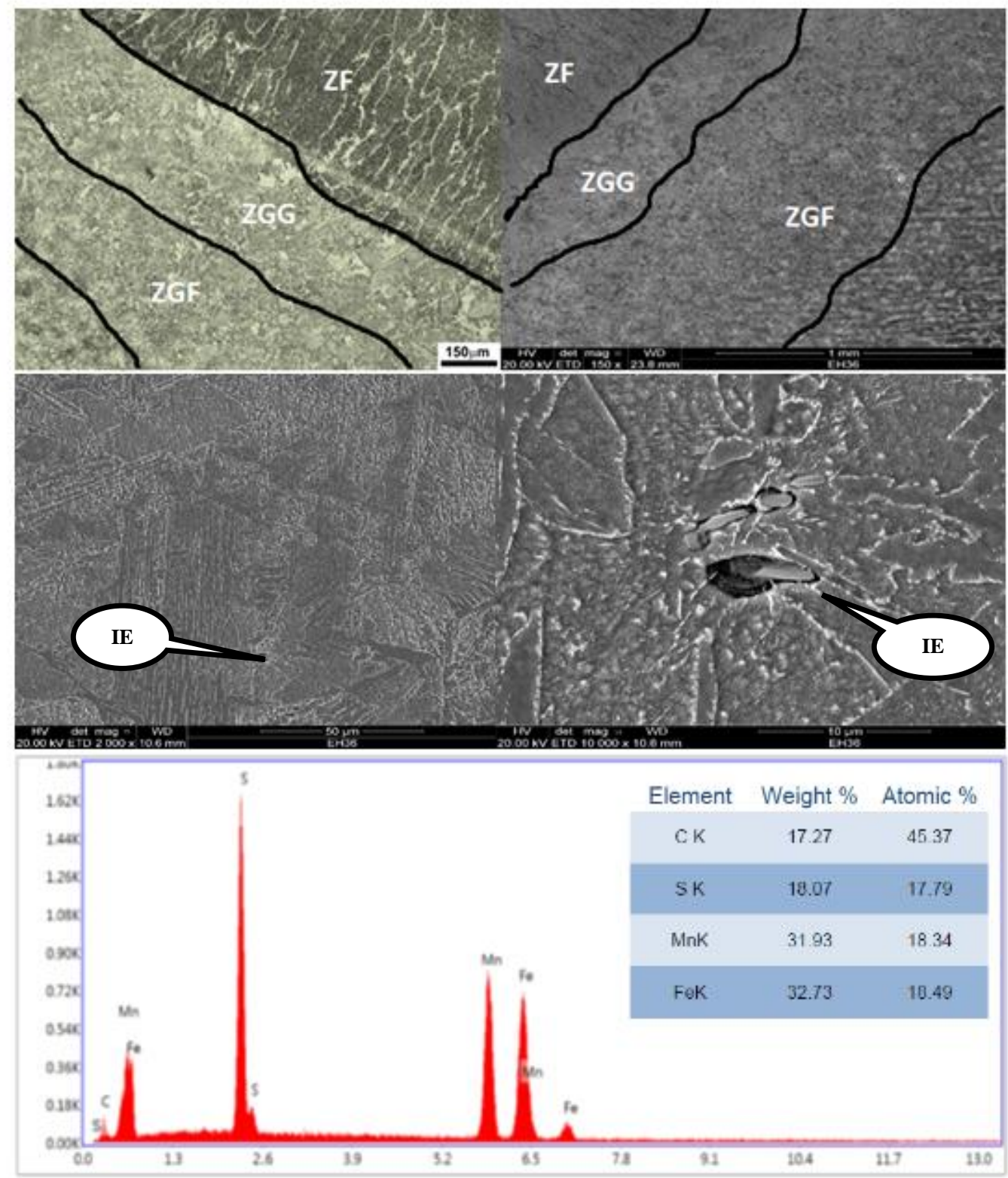

Nucleus,v.12,n.1,abr.2015 
As imagens de microscopia eletrônica da região de grão grosseiros apresenta uma microestrutura com grande quantidade de bainita. A imagem apresentada na figura acima mostra que há inclusões alongadas de sulfeto de manganês (IE), fato comprovado pela análise de EDS.

Figura 7. Mudança da estrutura do cordão de solda.

As microestruturas apresentadas na figura acima mostram a mudança na estrutura do cordão inferior pela deposição do cordão superior, onde é observado um refino da estrutura de grão colunares devido à imposição do ciclo térmico. Nas microestruturas apresentadas na figura acima é possível observar a presença de ferrita poligonal (FP), ferrita acicular (FA) e ferrita de contorno de grão (FG). Nas micrografias obtidas por microscopia eletrônica de varredura e possível observar a presença de inclusões (IE). As inclusões foram analisadas por micro análise químicas por EDS mostrou que as inclusões observadas na zona fundida são provenientes do fluxo presente no arame tubular. Os valores médio de extensão da zona afetada pelo calor foi de $2 \mathrm{~mm}$ para ambos os lados, valores do coeficiente de diluição foi de $14 \%$

Figura 5. Espectrometria de emissão atômica.

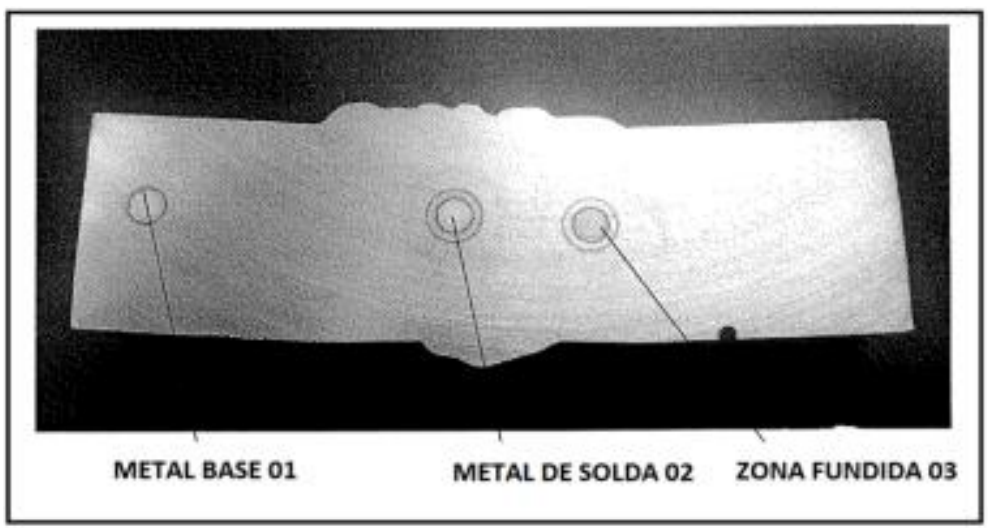

A figura apresenta as regiões onde foram extraídas amostras da junta para análise química das três regiões: R1 Metal Base, Região R2 Metal de solda e Região R3 Interface entre zona fundida e Zona afetada pelo Calor por Espectrometria de Emissão Atômica.

Tabela 1. Componente químico encontrado na amostra.

\begin{tabular}{|l|l|l|l|l|l|l|l|}
\hline & $\begin{array}{l}\mathrm{C} \\
(\%)\end{array}$ & $\begin{array}{l}\text { SI } \\
(\%)\end{array}$ & $\begin{array}{l}\text { Mn } \\
(\%)\end{array}$ & $\begin{array}{l}\text { P } \\
(\%)\end{array}$ & $\begin{array}{l}\text { S } \\
(\%)\end{array}$ & $\begin{array}{l}\text { Cu } \\
(\%)\end{array}$ & $\begin{array}{l}\text { Mo } \\
(\%)\end{array}$ \\
\hline R1 & $\mathbf{0 . 1 4}$ & $\mathbf{0 . 2 5}$ & $\mathbf{0 . 9 5}$ & $\mathbf{0 . 0 1}$ & $\mathbf{0 . 0 1}$ & $\mathbf{0 . 0 0}$ & $\mathbf{0 . 0 0}$ \\
\hline R2 & $\mathbf{0 . 0 5}$ & $\mathbf{0 . 6 6}$ & $\mathbf{1 . 4 1}$ & $\mathbf{0 . 0 1}$ & $\mathbf{0 . 0 0}$ & $\mathbf{0 . 0 2}$ & $\mathbf{0 . 0 0}$ \\
\hline R3 & $\mathbf{0 . 1 5}$ & $\mathbf{0 . 2 6}$ & $\mathbf{0 . 9 8}$ & $\mathbf{0 . 0 2}$ & $\mathbf{0 . 0 2}$ & $\mathbf{0 . 0 0}$ & $\mathbf{0 . 0 0}$ \\
\hline
\end{tabular}

Tabela 22. Componente químico encontrado na amostra.

\begin{tabular}{|l|l|l|l|l|l|l|l|}
\hline & $\begin{array}{l}\mathrm{Ni} \\
(\%)\end{array}$ & $\begin{array}{l}\mathrm{Cr} \\
(\%)\end{array}$ & $\begin{array}{l}\mathrm{Al} \\
(\%)\end{array}$ & $\begin{array}{l}\mathrm{Pb} \\
(\%)\end{array}$ & $\begin{array}{l}\mathrm{Ti} \\
(\%)\end{array}$ & $\begin{array}{l}\text { Nb } \\
(\%)\end{array}$ & $\begin{array}{l}\mathrm{V} \\
(\%)\end{array}$ \\
\hline R1 & $\mathbf{0 . 0 0}$ & $\mathbf{0 . 0 1}$ & $\mathbf{0 . 0 2}$ & $\mathbf{0 . 0 0}$ & $\mathbf{0 . 0 0}$ & - & - \\
\hline R2 & $\mathbf{0 . 0 0}$ & $\mathbf{0 . 0 2}$ & $\mathbf{0 . 0 1}$ & $\mathbf{0 . 0 0}$ & $\mathbf{0 . 0 4}$ & $\mathbf{0 . 0 0 2}$ & $\mathbf{0 . 0 1}$ \\
\hline R3 & $\mathbf{0 . 0 0}$ & $\mathbf{0 . 0 1}$ & $\mathbf{0 . 0 2}$ & $\mathbf{0 . 0 0}$ & $\mathbf{0 . 0 0}$ & - & - \\
\hline
\end{tabular}




\section{Soldabilidade do Aço EH 36.}

A soldabilidade do aço EH-36 e medida através de uma série de requisitos dos materiais e respectivas soluções para uma junção eficiente e de alta qualidade, a elevada energia utilizada na soldagem pode gerar transformações micro estruturais diminuindo a resistência na zona afetada pelo calor, com os grãos menores. O aço EH 36 apresenta carbono equivalente na faixa de 0,179 e atrelado ao processo de laminação controlada a quente, resfriamento acelerado proporcionando grãos de ferrita com microconstituinte perlita dispersas, o que oferece a essa classe de aço uma excelente soldabilidade (WANG, 2002). Uma das formas de avaliar a soldabilidade de um aço é através do cálculo do carbono equivalente $\left(\mathrm{C}_{\mathrm{eq}}\right)$. A equações 1 apresenta a equação usualmente aplicadas no cálculo do $\mathrm{C}_{\mathrm{eq}}$ (WANG, 2002).

$$
C_{\text {eq }}=C+\frac{M n}{6}+\frac{(C r+M o+V)}{5}+\frac{(N i+C u)}{15}=0,179
$$

(Equação 1)

$\mathrm{O} \mathrm{C}_{\mathrm{eq}}$ é empregado para relacionar a temperabilidade do aço e sua soldabilidade. Quanto maior o valor do $\mathrm{C}_{\mathrm{eq}}$, pior a soldabilidade. A faixa ideal para que se obtenha uma boa soldabilidade seja inferior a 0,41. Para materiais que apresentem valores de $\mathrm{C}_{\mathrm{eq}}$ acima desse valor devem ser usados eletrodos do tipo básico ou com baixos teores de hidrogênio e, para materiais onde o $\mathrm{C}_{\mathrm{eq}}$ atinge ou supere 0,45 , recomendase que a metal base deva ser pré-aquecido. Analisando as equações (1) nota-se que a presença de elementos de liga pode alterar a soldabilidade do aço.

\section{RESULTADO E DISCUSSÃO}

As análises macro gráficas mostram sinais de bandeamento devido à existência de segregação química herdada do estágio de solidificação e expansão em camadas pela deformação de laminação no metal base. Os resultados apresentados na tabela 5 mostram que não ocorreu variação significativa quando comparadas as regiões R1 e R3.

Figura 6. Ensaio de micro dureza brinell.

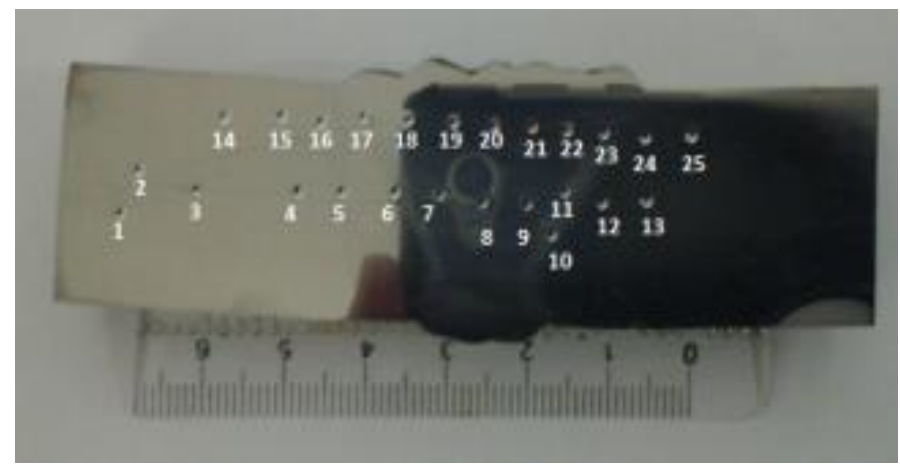


Tabela3. Resultado da micro dureza da amostra.

\begin{tabular}{|r|r|r|r|r|r|}
\hline Pt. & $\begin{array}{c}\boldsymbol{~} \mathbf{d} \\
(\mathbf{m m})\end{array}$ & $\begin{array}{c}\text { HB } \\
\left(\mathbf{K g f} / \mathbf{m m}^{2}\right)\end{array}$ & $\mathbf{P t .}$ & $\begin{array}{c}\boldsymbol{~} \mathbf{d} \\
(\mathbf{m m})\end{array}$ & $\begin{array}{c}\text { HB } \\
\left(\mathbf{K g f} / \mathbf{m m}^{2}\right)\end{array}$ \\
\hline 1 & 1,26 & 140,01 & 14 & 1,22 & 150,07 \\
\hline 2 & 1,27 & 137,64 & 15 & 1,20 & 155,48 \\
\hline 3 & 1,10 & 187,08 & 16 & 1,18 & 161,17 \\
\hline 4 & 1,22 & 150,07 & 17 & 1,05 & 206,35 \\
\hline 5 & 1,17 & 164,12 & 18 & 1,05 & 206,35 \\
\hline 6 & 1,13 & 176,72 & 19 & 1,07 & 198,32 \\
\hline 7 & 1,04 & 210,54 & 20 & 1,06 & 202,28 \\
\hline 8 & 1,06 & 202,28 & 21 & 1,06 & 202,28 \\
\hline 9 & 1,05 & 206,35 & 22 & 1,05 & 206,35 \\
\hline 10 & 1,10 & 187,08 & 23 & 1,09 & 190,73 \\
\hline 11 & 1,08 & 194,47 & 24 & 1,15 & 170,26 \\
\hline 12 & 1,16 & 167,15 & 25 & 1,18 & 161,17 \\
\hline 13 & 1,20 & 155,48 & & & \\
\hline
\end{tabular}

As regiões apresentadas na tabela 5 na cor verde representam à dureza no metal de base as regiões em laranja representam os valores de dureza encontrados na zona afetada pelo calor enquanto os valores em vermelho representam os valores de dureza na região fundida. Os valores foram obtidos com a utilização do ensaio de dureza brinell utilizando um durometro da marca Wolpert modelo EXT-0349, foi endentado a amostra com uma esfera de $10 \mathrm{~mm}$ de diâmetro, com uma carga de 500kgf de 10 a 15 segundos. Como poder ser observado na tabela 5 a um aumento de dureza do metal base para a região fundida, onde o valor médio foi calculado através do programa de estatística SPSS, os valores que se encontram fora do valor médio \pm 1 o valor do desvio padrão, após a exclusão destes valores a dureza média foi estimada nas três regiões: Metal Base 157 \pm 9 HB; Zona Afetada pelo Calor 190 \pm 3 HB e Zona Fundida $204 \pm 2 \mathrm{HB}$, portando a zona fundida apresenta um acréscimo de aproximadamente $30 \%$ na dureza, o que era esperado uma vez que o metal de adição deve apresentar valores de dureza e resistência à tração superior ao metal base.

\section{CONCLUSÃO}

Foi caracterizada uma junta soldada de aço estrutural EH-36. Os resultados da caracterização macroestrutural mostraram uma Zona Afetada pelo Calor estreita, com cerca de $2 \mathrm{~mm}$ de extensão. A microestrutura na ZAC mostrou a presença de ferrita poligonal, ferrita de widmanstatten, ferrita acicular e bainita. Também foi observada a presença de inclusões de sulfeto de manganês, fato este que pode dificultar a utilização deste material para o transporte de petróleo uma vez que estas inclusões funcionam como armadilhas para o hidrogênio, portanto pode levar o material a apresentar em serviço trincas induzido por hidrogênio na presença de H2S. Na zona fundida foi observada uma redução no tamanho dos grãos colunares devido ao efeito do ciclo térmico imposto na deposição do cordão superior. Foi 
observada na zona fundida a presença de inclusões de escoria com cerca de $1 \mu \mathrm{m}$ espalhadas ao longo do cordão.

\section{REFERENCIAS}

ARAUJO, Douglas Bezerra de. Metodologia para uso de simulação física do estudo da ZAC e na obtenção de diagramas CCT para soldagem. 2008. Dissertação de Mestrado, Universidade Federal de Uberlândia.

WANG, S. H.; CHIANG, C. C.; CHAN, S. L. I. Effect of microstructural texture on the creep behavior. Journal of Materials Science, v.37, n.17, p. 3733-3737, 2002. 